RESOURCE ALLOCATION

\title{
Gender, ageing, and injustice: social and political contexts of bioethics
}

\section{$S$ Dodds}

J Med Ethics 2005;31:295-298. doi: 10.1136/jme.2003.006726

Correspondence to: S Dodds, Associate Professor in Philosophy, Institute of Social Change and Critical Inquiry Faculty of Arts, University of Wollongong, NSW 2522, Australia; sdodds@ uow.edu.au

Received 8 October 2003 In revised form 8 February 2004 Accepted for publication 14 February 2004

\begin{abstract}
There has been considerable work in bioethics addressing injustice and gender oppression in the provision of healthcare services, in the interaction between client and healthcare professional, and in allocation of healthcare services within a particular hospital or health service. There remain several sites of continued injustice that can only be addressed adequately from a broader analytical perspective, one that attends to the social and political contexts framing healthcare policy and practice. Feminist bioethicists have a strong track record in providing this kind of analysis. Using current Australian aged care and welfare policy this paper demonstrates some of the ways in which issues of gender, age, and social inequity shape bioethical debate, policy, and practice in the areas of aged care and welfare provision. The author develops an argument that demonstrates the gender injustice underlying health care and welfare policy. This argument recognises the inevitability of human dependency relations, and questions the adequacy of current political theories to address the requirements for full and equal citizenship. The author shows that an adequate analysis of the ethics of aged healthcare depends on sufficient consideration of the social and political context within which healthcare policy is framed and an adequate understanding of human dependency.
\end{abstract}

W riting in bioethics has acknowledged the ways in which physician-patient interactions are sometimes affected by relations of injustice, for example where decisions are made to refuse or withhold quality treatment from people who cannot afford expensive treatment, ${ }^{12}$ or where patients' decision making in healthcare is ignored. Further, the medical paternalism of the past, which served so successfully to discount the voices of women and other disadvantaged groups, has largely been overturned in favour of respect for client autonomy. ${ }^{3}$ Healthcare workers are now more aware of and alive to the ways in which their interactions with patients can perpetuate injustice and gender biases. I argue in this paper, however, that the attention given to gender and power relations in healthcare has tended to have too narrow a focus. In the case of aged care, ethical concern has centred on justice in overall distribution of healthcare resources and the specific patient-physician interaction.

This paper aims to identify some of the ways in which feminist approaches to bioethics uncover otherwise overlooked areas of injustice and power relations in healthcare and wider social policy. I demonstrate how a feminist approach to bioethics reveals gender bias in aged care policies, using changes over the past three decades in Australian aged healthcare, welfare, and housing policy to illustrate my argument. I believe that many of the points I draw out in the Australian context are reflected in the social and health policy of other countries. The concerns I identify, however, are largely overlooked in the dominant bioethical literature on ageing, because of assumptions widely accepted in contemporary Western societies about care and dependency. ${ }^{45}$

\section{THE COST OF CARING FOR THE ELDERLY}

There are two key themes in much of the bioethical literature concerning elderly patients. Foremost of these is the emphasis on the economic or resource implications of providing healthcare for an ageing population. Several books and articles have been written which focus on just distribution of healthcare resources and aged based rationing of healthcare. $^{26-9}$ The demographic data in most industrialised states shows that, with improved public health policies and access to healthcare, the population is steadily ageing. The ethical debate concerning how to justify rationing healthcare for elderly patients or seeking justifications for continuing costly treatment tend to hinge on a conception of the state as a cooperative association designed for mutual protection. Debate will centre on whether a justification can be given for allocating costly care to elderly patients based on considerations like: long term prognosis, "fair innings", Quality Adjusted Life Years (QALYs), ability to pay, and so on. The gender or social disadvantage of the elderly people seeking care, or those who provide care is assumed largely to be irrelevant (see, for example, Moody ${ }^{2}$ ). In these debates, the central question is the fairness of the distribution of healthcare resources between different age groups or prognoses.

Within that approach, each elderly patient is conceived of as an individual who is entitled to a portion of social resources in virtue of their contribution. They are thus understood to be in one way or another entitled to healthcare resources comparable to their contribution to the overall social product. These approaches allow that elderly patients are not entitled to unlimited resources, but that their previous status as contributors to the social good means that their entitlement to healthcare resources continues for a period after their active contribution has ended due to retirement, disability, or illness.

This particular understanding of the "social contract" wherein the state is justified as a structure for providing for mutual needs and mutual benefit among equal citizens has been criticised by feminists on a number of grounds. ${ }^{10}{ }^{11}$ It is a view of society, construed as "an association of equals, conceived as individuals with equal powers, equally situated in competition for the benefits of the human condition" (see Kittay, p $\left.10-11^{4}\right)$. Contributions to the state are understood principally in terms of participation in the paid workforce, so the labour undertaken (mostly) by women in unpaid care for children and other dependents and in the reproduction of the 
needs of the worker (domestic labour) are underrated or wholly overlooked as contributions meriting the protection of the state and access to the state's healthcare resources. (For further discussion of how the "invisibilisation" of unpaid home care has developed in the US see Parks ${ }^{12}$ ). This is unnoticed, due to the slippage between treating individuals as separate individuals and as "heads of households" who gain the means of existence through paid labour. ${ }^{11}$ (For an extended discussion of the theoretical presuppositions that make human dependency problematic for liberal political theory see Kittay. ${ }^{5}$ ) Such an approach can not readily justify expenditure of resources on other "non-productive" members of the society, for example, children (except in virtue of their assumed or potential future contributions) and people whose chronic illness or disability render them unable to participate in paid work as that is currently constructed. ${ }^{411} 13$ Women are particularly badly affected, in these calculations, by the understanding of members of a society as independent atomised wage earners, as I demonstrate below.

\section{AUTONOMY AND COMPETENCE TO MAKE HEALTHCARE DECISIONS}

A secondary focus of bioethical engagement with aged care concerns the tensions between a general ideal of respecting autonomy and a desire to protect those elderly patients whose autonomy is compromised or diminished against the choices they might make for themselves. Mainstream bioethics has tended to restate the expectation that, unless a person is deemed to be clinically incompetent, their competence should be respected (noting the tendency to treat elderly patients paternalistically), or to treat the elderly patient's wishes as subordinate to family wishes or institutional needs. More critical works, however, go further to question the contexts in which competency assessments are made, by attending to wider social and economic circumstances. These works express significant concern about the ways in which an individual's competency will come under question as a direct result of limited healthcare resources, rather than some specific incapacity of the elderly patient. ${ }^{14}{ }^{15}$ The use of competency assessments to address resource problems may reflect ageist assumptions and a failure to recognise the interests of elderly people that extend beyond their health interests. ${ }^{16}$

Barbara Secker has argued that as women are more likely to be dependent on public healthcare services, and on welfare, they are also more likely to find their competence questioned and subject to competency assessment, and more likely to have their choices overridden. ${ }^{14}$ She draws attention to the ways in which social stereotypes exacerbate the effects of women's exposure to competency assessments where older women are disabled, lack communication skills, are members of ethnic minorities, or are otherwise socially disadvantaged. ${ }^{13} 141718$ Secker's approach to examining the relationships among gender, poverty, and competence assessment, which takes into account the different social circumstances of elderly men and women (as demographic groups) and which ties these conditions to gender injustice in access to paid employment, wealth, and private housing, provides a good starting point for critically reassessing the ethical significance of policies relating to ageing. Her approach helps to identify some of the gender and power biases built into aged service provision, because her concern for the autonomy and competence of patients is situated within the social, gender, and economic contexts of competency assessment. That is, she uses a feminist approach to the bioethical analysis of competency assessment.

In considering public policy relating to aged care from a feminist point of view, the two axes of gender and age need to be addressed. Along the first axis lies the ethical assessment of the kinds of care that elderly women receive; the second measures the effects of women's traditional and current social roles as paid and unpaid carers. In spelling out the ways in which women are particularly affected in aged care I draw on Eva Feder Kittay's work on the dependency relations created when some members of a society care for others. ${ }^{45}{ }^{19}$ To give the account some context, I examine these in light of trends in Australian aged care, welfare, and housing policy. It is worth noting that Australia, like Canada and the UK, has enjoyed a relatively robust system of social welfare. Nonetheless, as in the UK and Canada, recently there has been a significant drop in resources allocated to social welfare provision and there has been a concurrent shift to a culture of "mutual obligation" where social services are thought to depend not solely on need, but on need together with the expectation that social welfare recipients will contribute towards their own care and welfare.

Although I focus on the Australian context, the general policy trends described here resonate through North America and the United Kingdom. The trend towards increased reliance on unskilled home based care and the unpaid or underpaid labour that is characteristic of such care is perhaps even more obvious in the United States. The lack of universal access to healthcare (publicly or privately funded) in the United States leaves a growing proportion of older Americans who need basic care dependent on private resources and unpaid care (see Parks, p 16-22 ${ }^{12}$ ).

\section{AGED CARE, HOUSING, AND WELFARE IN AUSTRALIA}

Australia has a dual (public/private) healthcare system, individuals or families can elect to pay private health insurance to give them greater access and control over elective healthcare procedures and to allow individuals to avoid long public hospital queues for non-elective treatment. Alternatively, all Australians are entitled to free healthcare in public hospitals and from those general practitioners who "bulk bill" through the public health system (Medicare); they may also access subsidised healthcare, paying a proportion of the practitioner's or hospital's fee, and having the remainder paid by Medicare. Taxpayers pay a graduated Medicare levy to support the public healthcare system. It is generally accepted in Australia that there is a "crisis" in the Medicare system, as those who are fully dependent on the public system have difficulty finding general practitioners willing to bulk bill, and find themselves on long waiting lists for hospital care. At the same time, physicians argue that the government remuneration for bulk billing is inadequate to cover their insurance and other practice costs. The Australian government has encouraged citizens to take out private health cover with tax rebates for their private healthcare premiums. Some observers might see this as a way to reduce the load on the public healthcare system; others view it as part of a general degradation of universal access to public healthcare. This shift can be expected to have the long term effect of reducing access to quality care services for poorer Australians.

Elderly Australians seeking access to healthcare are more likely than the average to rely on public healthcare. Within the public healthcare system there has been a shift towards community based healthcare and the preservation of hospital services only for the acutely ill. In very many cases, people who are discharged from hospital in Australia are still dependent on nursing care-to clean and change dressings, to maintain intravenous drips, and to assist with activities of daily living: bathing, eating, toileting, and walking. 


\section{CHANGES IN AGED CARE AND NURSING HOME POLICY}

In response to the growth in the number of people accessing aged care (that is elderly people using healthcare services, rehabilitation, and nursing home care), there has been a general recognition among policymakers and others in the aged care sector that Australia has had "an overly large and expensive long term institutional care sector, and a correspondingly underdeveloped home based care sector" ${ }^{20}$ The government has focused its policies to encourage or force a shift away from reliance on institutional care, towards community based services. Since 1985 the aged care system has been undergoing "a lengthy period of substantial reform". ${ }^{20}$ As a result, although the number of older Australians is growing, the proportion of hospital and nursing home beds available is shrinking. ${ }^{20} 21$

The emphasis on home based care often presupposes that there is a family member available to provide basic care for dependent elderly people, and so that healthcare support, in the form of community nurses, is only required to monitor health. People who care for family members at home can be eligible for the "carer's pension". However, that pension is means tested (where the wealth of both the person cared for and the person who is providing the care is assessed) and provides only a minimal payment to cover the very basic needs of the carer. The means testing of the carer's pensions can help to reinforce attitudes that women ought to provide high quality care for nothing, as other family members, anticipating their parent's inheritance, are often reluctant to allow the family home (the key source of wealth among Australians) to be sold to compensate the otherwise unpaid family carer. Similarly, following a reduction in government subsidies for pharmaceuticals, anecdotal accounts suggest that the meagre carer's pension is often spent on the drugs needed by the person cared for that they cannot afford on their old age or disability pension.

The Australian government has also reformed policy relating to nursing homes, in part to encourage private entrepreneurs to invest in nursing homes and to run them for profit. The Aged Care Act 1997 made substantial changes to the way nursing homes are funded. Prior to the introduction of the act, a fixed percentage of funding received by owners of aged care facilities was dedicated to care, and had to be spent on care, including the salaries of nursing staff. Funding could not be diverted to non-care staff, to capital maintenance or to profit. This requirement was removed under the 1997 act. One effect of the changes has been an exodus of experienced nurses from private nursing homes, because the effective deregulation of nursing home funding has led to lower wages for professional carers. This, in turn, has led to inadequate staffing levels, and what is described as an "inappropriate skill mix in many facilities". ${ }^{22}$

\section{WOMEN AND AUSTRALIAN AGED CARE POLICY}

The Australian government has provided a number of tax breaks for what are known as "self funded retirees" (those who are not dependent on government pensions for their welfare after retirement), while reducing the relative value of the aged pension. The move towards encouraging private savings and superannuation, and away from the public pension, to support people in old age may have serious implications for older women who may not be able to qualify for an occupational pension. ${ }^{23}$ Rising divorce rates also reduce spousal pension benefits; on average, women are paid less than men, "thereby reducing their ability to save for retirement and increasing the likelihood that pensions based on earning histories will continue to be lower for women than for men". ${ }^{23} 24$
On average, older women outlive their male partners, are less wealthy and, if they are widowed, their familial assets are likely to have been sold, following current government policy, to pay for the nursing home care of the woman's husband in his final years (for a discussion of the feminisation of poverty see Gimenez ${ }^{25}$ ). Elderly women who need care are less likely than elderly men to be able to afford private nursing home care or to be able to afford private home based care. Older women are more likely to end up dependent on public aged care pensions, living in hostels for the elderly, and in receipt of care from poorly trained nurses. Further, a great many of the people who provide unpaid home based care to family members are women who also work in the paid labour force, but whose careers-hence their long term wealth and capacity to provide for their own care in old age-are adversely affected by the expectation that they will provide unpaid care for others at various points in their work lives. ${ }^{26} 27$

Where women provide paid care, the recent changes to nursing home policy and the ongoing undervaluing of nursing (and women's work more generally) ${ }^{28}$ mean that these women are often poorly trained, poorly paid, and open to immense physical and emotional pressures within their work. $^{26}$ The current approach to social policy concerning ageing in Australia, I conclude, contributes to gender injustice. The injustice affects women as carers and as recipients of care. Australian aged care policy contributes to gender injustice despite appearing to focus concern on the needs of ageing Australians irrespective of gender. It is, in effect, gender blind. The policy is founded on the inconsistent approach of emphasising the needs of individual elder Australians, while assuming that those individuals are members of (gendered) families in which there is both ongoing income based on paid labour and "free" domestic care. Once these assumptions are unpacked and the gender differentiated effects of the policies are revealed, their significance for women's equal participation in society, their access to quality aged care, housing, and social support and their empowerment become much clearer. It is just this kind of social, political, economic, and gendered interrogation that is typical of a feminist approach to bioethics. As Parks writes, home care is a feminist issue, not only because it affects a greater number of women than men (both as carers and as those cared for). "Home care is a feminist issue because women have been defined as caretakers. What matters isn't the numbers of female caretakers but their embeddedness in caring relationships and the gendered burden of care that impacts women's social, political, economic, and emotional lives" ( see Parks, p $4^{12}$ ).

\section{TOWARDS A FEMINIST APPROACH TO THE ETHICS OF AGED CARE POLICY}

According to my analysis there is an implicit gender bias built into current Australian aged care policy and this gender bias reflects a conception of citizens as rational, physically able, productive individuals. Any limitations on such individuals are to be construed as either chosen (and hence the cost should be borne by the individual) or as problems peculiar to the individual, rather than as a predictable effect of dominant social norms, given the kinds of things human people are. ${ }^{4}$ In her work on care and dependency Kittay offers an analysis of care and dependency that shifts the focus from individual "lack" on the part of the cared for, to a recognition of the inevitable demands placed on human adults to provide care, and recognition of the ways that the activity of caring for another makes the carer also dependent on others for their material and social needs. ${ }^{45}{ }^{19}$ Kittay emphasises the burdens placed on others to provide for the needs of the carer, when people take on the (ordinary human) task of what she calls 
"dependency work" (see Kittay, p 525 $5^{19}$ ). In caring for someone who is (to some degree) dependent, the dependency worker becomes dependent on others.

The dependency worker requires others who will see to it that resources are available to meet the needs of both herself and the needs of her charge. She also needs assurance that when her care for another impedes her ability to care for or fend for herself, she can depend on another for sustenance and aid, and that when she is unable to care for her charge another will (see Kittay, p $525^{19}$ ). According to Kittay, existing liberal political theories, that view the just society as one in which all people are treated as free and equal, are deficient to the extent that those theories fail to recognise the effects of human dependency on the liberty and equality of dependency workers. Women's social citizenship depends on recognition of the social goods of dependency care and relationships of caring; equality demands of citizenship the capacity to respond to those in need with care. "But full social citizenship requires that if we are called upon to care, we can fulfil these duties without losing our ability to care for ourselves, and that in caring for another, the full burden of support as well as care for the one dependent on us will not fall upon our shoulders alone. Without such assurance, we have not yet attained the powers and capacities to function as free and equal citizens" (see Kittay, p 1315).

If public policy is to recognise women as citizens, if it is to recognise the growth in divorce and the alienation of parents from their adult children, it can no longer shape policy around the archaic form of the patriarchal family. In that social institution, in which the head of the household provides the financial support for meeting a family's material needs, there is also a full time carer able to transform the pay of the working head of the household into the material and emotional supports for life of the family members and civic participation (appropriate to one's role in the family). Such a view of social relations allows dependency work to go unrecognised when it is carried out without pay, and undervalued when it is carried out for pay. By placing the inevitable dependence of humans on one another at the centre of her analysis, Kittay's approach forces recognition of the significance of this work. An important human need is met through the carer's labour, but this care comes at a cost to the carer in her ability to support herself and to participate as a full citizen. Kittay's approach challenges the atomistic individualism of most liberal approaches to social policy and bioethics, and it explains why in a society in which most dependency work is done by women, women are often exploited by the arrangement, have reduced wealth, and are less likely to receive quality care when they become dependent themselves. The conceptual groundings of the social contract need to be revised to redress the injustice that results from those atomistic assumptions. Such revisions will foreground the relational developmental nature of human agency and citizenship.

\section{CONCLUSIONS}

This paper has used the case of aged care, housing, and welfare policy in Australia to demonstrate the gender inequities that are overlooked in public policy, in dominant political theory and in the bulk of mainstream bioethical discourse on aged care. Through a feminist approach to bioethics, a number of unargued assumptions of the social context of aged care debates have been uncovered. Feminist approaches to bioethics locate debate in the social, economic, gender, and power relations that may otherwise go unchallenged. Unless those wider aspects of social relations are carefully examined, and appropriately challenged, bioethical contributions to debate about aged care will continue to provide very partial analyses, which overlook the significance of gender and power in assessments of justice. The analysis presented here demonstrates the injustice and gender inequity of current aged care and welfare policies.

\section{ACKNOWLEDGEMENT}

The author wishes to thank Angela Pratt for her research assistance, especially in identifying relevant work on Australian government policy.

Research for this paper was supported in part by funds from the Institute of Social Change and Critical Inquiry.

Competing interests: none

\section{REFERENCES}

1 Caplan AL. If I were a rich man could I buy a pancreas? And other essays on the ethics of health care. Bloomington: Indiana University Press, 1992.

2 Moody HR. Ethics in an aging society. Baltimore: Johns Hopkins Press, 1992.

3 Dodds S. Choice and control in feminist bioethics. In: Mackenzie C, Stoljar N, eds. Relational autonomy in context: feminist perspectives on autonomy, agency and the social self. New York: Oxford University Press, 2000:213-35.

4 Kittay EF. Taking dependency seriously: the Family Medical Leave Act considered in the light of the social organization of dependency work and gender equality. Hypatia 1995; 10:8-29.

5 Kittay EF. Love's labor: essays on women, equality and dependency. London: Routledge, 1999.

6 Daniels N. Just health care. London: Cambridge University Press, 1985.

7 Brock DW. Justice, health care and the elderly. Philos Public Aff 1989; 18:297-312

8 Veatch RM. How age should matter: justice as the basis for limiting care to the elderly. In Winslow GR, Walters JW, eds. Facing limits: ethics and health care for the elderly. Boulder: Westview, 1993:211-29.

9 Binstock RH, Post SG, eds. Too old for health care. Baltimore: Johns Hopkins University Press, 1991.

10 Pateman C. The disorder of women. Cambridge: Polity Press, 1989:1 18-40.

11 Okin SM. Justice, gender and the family. New York: Basic Books, 1989.

12 Parks JA. No place like home? Feminist ethics and home health care. Indianapolis: Indiana University Press, 2003:9-32.

13 Silvers A. Reconciling equality to difference: caring (f)or justice for people with disabilities. Hypatia 1995; 10:30-56.

14 Secker B. Labelling patient (in)competence: a feminist analysis of medico-legal discourse. J Soc Philos 1999;30:295-314

15 Pepper-Smith R, Harvey WRC. Competency assessments in discharge planning and the question of intergenerational justice. Westminster Affairs 1990;3:3-5.

16 Dodds S. Exercising restraint: autonomy, welfare and elderly patients. J Med Ethics 1996;22:160-3.

17 Lock M. Anomalous women and political strategies for aging societies. In: S Sherwin S, Baylis F, Bell M, et al. The politics of women's health: exploring agency and autonomy. Philadelphia: Temple University Press, 1998:48-63.

18 Bell M, Mosher J. (Re)fashioning medicine's response to wife abuse. In: Sherwin S, Baylis F, Bell M, et al. The politics of women's health: exploring agency and autonomy. Philadelphia: Temple University Press, 1998:222-3.

19 Kittay EF. A feminist public ethic of care meets the new communitarian family policy. Ethics 2001;111:523-47.

20 Gibson D, Angus P, Braddock D, et al. Deinstitutionalisation: the move towards community-based care. In: Australian Institute of Health and Welfare. Australia's welfare. Canberra: Australian Institute of Health and Welfare, 2001;99-139: 113 .

21 Gray L. Beyond the two year review: the new generation of issues in aged care? Australas J Ageing 2001;20:123-6.

22 Armstrong F, Witham H. Federal election 2001. Aust Nurs J 2001;8:26-9.

23 Rosenman L, Warburton J. Retirement policy, retirement incomes and women. In: Borowski A, Encel S, Ozanne E, eds. Aging and social policy in Australia. Melbourne: Cambridge University Press, 1997:157-73.

24 Heycox K. Older women: issues of gender. In: Borowski A, Encel S, Ozanne E, eds. Aging and social policy in Australia. Melbourne: Cambridge University Press, 1997:94-118.

25 Gimenez ME. The feminization of poverty: myth or reality? In: Fee $\mathrm{E}$ Krieger N, eds. Women's health, politics, and power: essays on sex/gender medicine, and public health. Amityville, NY: Baywood Publishing Company, 1994:287-305

26 Collopy B, Dubler N, Zuckerman C. The ethics of home care: autonomy and accommodation. Hastings Cent Rep 1990;20:16.

27 Watson EA, Mears J. Women, work and care of the elderly. Aldershot: Ashgate Publishing Company, 1999.

28 Graycar R, Morgan J. The hidden gender of law. Annandale, NSW: Federation Press, 2002. 